\title{
SOSIAALINEN MEDIA ITSENSÄ ILMAISUN, SOSIAALISEN PÄÄOMAN JA HYVINVOINTIVAIKUTUSTEN VÄLITTÄJÄNÄ
}

Niko Männikkö: TtT, Tki-päällikkë, Oulun ammattikorkeakoulu Oy; tutkijatobtori, Oulun yliopisto

mannikkon@gmail.com

Janus vol. 29 (4) 2021,398-404

Sosiaalisen median (some) suosio on lisääntynyt merkittävästi 2000-luvun alusta lähtien mullistaen samalla ihmisten viestintätapoja. Laajasti tarkasteltuna sosiaalinen media käsittää digitaaliset sovellukset ja sähköiset työkalut, jotka mahdollistavat käyttäjien sosiaalisen vuorovaikutuksen (Moreno 2014). Määritelmän mukaan palveluvalikoimaan kuuluvat tekstiviestisovellukset, verkkoyhteisöpalvelut sosiaaliset (Instagram, Snapchat, Facebook ja TikTok) ja pelimediat (Fortnite ja Minecraft). Sosiaalinen media tarjoaa rajattomat mahdollisuudet selata tai toistaa muiden käyttäjien sisältöä sekä tuottaa ja jakaa myös omaa sisältöä.

Sosiaalista mediaa käyttää maailmanlaajuisesti lähes neljä miljardia ihmistä. Kolme suosituinta sosiaalisen median alustaa ovat Facebook, Youtube ja WhatsApp (Statista 2021). Sosiaalisen median käyttö vakiintuu erityisesti teini-ikäisten arjessa (Rideout ym. 2019), mutta käyttö on laajaa ja yleistä myös aikuisilla (Eurostat 2019). Kuitenkin nuorten keskuudessa sosiaalinen media on ensisijainen vuorovaikutuskanavana (Nesi ym. 2018; Rideout ym. 2019). Ottaen huomioon teknologiavälineiden viime vuosina yhteiskuntaan tuomat muutosvaikutukset, ei ole yllättävää, että kaikkialla ollaan kiinnostuneita ymmärtämään syvällisemmin tämän tekniikan vaikutuksista ihmiseen.

\section{IHMISTEN VÄLINEN SOSIAALINEN vUOROVAIKUTUS SOSIAALISEN MEDIAN KANAVILLA}

Ihmisillä on perustavanlaatuinen tarve olla sosiaalisessa kanssakäymisessä toistensa kanssa (Baumeister ym. 1995), ja siihen sosiaalinen media tarjoaa laajan valikoiman työkaluja. Sosiaalisen median perusominaisuudet kuitenkin erottavat sen perinteisestä, kasvokkain tapahtuvasta vuorovaikutuksesta. Muutoskehysteorian (engl. transformation framework) mukaan näillä ominaisuuksilla voi olla merkittävä vaikutus siihen, miten ihmiset ovat vuorovaikutuksessa verkossa ja millainen yhteys sillä on heidän hyvinvointiinsa (Nesi ym. 2018).

Sosiaalisessa mediassa toiminta on usein aluksi julkisempaa kuin kasvokkain tapahtuvassa kanssakäymisessä, sillä se sallii samanaikaisen vuorovaikutuksen useamman ja jopa tuntemattomien henkilöiden kanssa. Julkisuus ilmenee tiettyjen toimintojen kautta, kuten valokuvan toimittamisena tuhansille Instagram-seuraajille. Viestintätavan julkisuus voi näyttäytyä myös pienemmillä foorumeilla esimerkiksi ryhmätekstiviestitoiminnoissa, joissa 
usein kommunikoidaan samanaikaisesti muutaman valikoidun ystävän kanssa.

Sosiaalisen median käyttäjillä on tietyillä kanavilla mahdollisuus käyttää asynkronisesti harkintaa ja aikaa viestien lukemiseen ja vastauksien muotoiluun sekä esittää itsensä valikoivan huolellisesti viestien ja valokuvien välityksellä. Toisaalta videoneuvottelutyökalut tarjoavat samassa määrin synkronisuutta kuin henkilökohtainen, kasvokkain tapahtuva vuorovaikutus. Termi "saatavuus" kuvastaa sisällön saatavuuden ja jakamisen helppoutta käyttäjän fyysisestä sijainnista riippumatta. Lisäksi viestittely sosiaalisen median kanavilla on mahdollista ilman fyysistä läsnäoloa ja joissain tapauksissa se voi olla luonteeltaan anonyymia.

Viestintätyyli sosiaalisessa mediassa voi olla tyyliltään kvantifioivaa, sillä näille verkkotoiminnoille on tyypillistä tykkäysten, seuraajien ja näkemysten määrä. Ystävien sisältöön kohdistettujen tykkäysten ja kommenttien näkeminen voi vahvistaa nuoren kokemaa yhteyden tunnetta muihin käyttäjiin, mutta se voi myös lisätä haavoittuneisuutta tietyn "aseman hakemiseen" ja vertaisvaikutuksiin.

Sosiaalisen median kommunikoinnista puuttuu usein lähes kokonaan kehoviestintä (ihmissuhteiden kehonkieli), kuten eleet, ilmeet, äänenpainot ja kosketus. Vuorovaikutuksesta saattavat siis puuttua keholliset vihjeet, jotka voisivat aktivoida vastapuolessa empaattisia reaktioita. Toisaalta visuaalisuus voi korostua etenkin valokuva- ja videoperusteisessa kommunikoinnissa, jonka muokkaustoimintojen kautta viestinnän välittämää miellyttävyyttä, järkyttävyyttä tai humoristisuutta voidaan korostaa. Pysyvyydellä viitataan siihen, missä määrin sisältö tai viestit ovat paikannettavissa ja käytettävissä alkuperäisen viestimisen jälkeen. Käyttäjät eivät aina ole tietoisia siitä, että joistain viestintätoiminnoista voi jäädä kauaskantoisia jälkiä verkkoon. Esimerkiksi Facebookissa jaettavat kuvat voivat olla löydettävissä hakutoiminnoilla vielä vuosienkin jälkeen.

Sosiaalinen media on siis muuttanut yksilön kanssakäymiseen liittyviä kokemuksia monella tapaa (Nesi ym. 2018). Se on lisännyt esimerkiksi kokemusten tiheyttä ja välittömyyttä, muuttanut vuorovaikutuksen laadullista luonnetta sekä luonut uusia mahdollisuuksia kompensoivan ja uudenlaisen käyttäytymisen omaksumiseen.

\section{SOSIAALISEN MEDIAN AKTIIVINEN JA PASSIIVINEN KÄYTTÖ}

Sosiaalinen median vaikutus ihmiseen riippuu paljolti siitä, miten näitä palveluja käytetään (Verduyn ym. 2015). Tutkimusten perusteella käytön taustalla olevat vaikutusmekanismit on yhdistetty hyvinvointikokemuksiin.

Sosiaalisen median aktiviteetit voidaan jakaa karkeasti kahteen kategoriaan: aktiiviseen ja passiiviseen käyttöön (Verduyn ym. 2015). Sosiaalisen median aktiivinen käyttö tarkoittaa tilannetta, jossa käydään suoraa vuorovaikutusta muiden henkilöiden kanssa. Tähän kuuluvat esimerkiksi suorat, kahdenkeskiset viestikeskustelut (esimerkiksi Facebookissa) tai muut ei kohdennetut kommunikointitavat (esimerkiksi tilapäivitykset tai linkkien jakaminen 
Facebookissa). Passiivisella käytöllä taas tarkoitetaan muiden ihmisten seuraamista ilman suoraa vuorovaikutusta toisten käyttäjien kanssa.

Sosiaalisen median aktiivisessa käytössä tietoa tuotetaan, kun taas passiivisen käytön aikana tietoa pääasiassa selataan. Äskettäin julkaistu meta-analyysi osoittaa johdonmukaisesti negatiivisen yhteyden passiivinen käytön ja hyvinvoinnin välillä (Liu ym. 2019), mutta toisaalta tutkimuksessa myös havaittiin, että aktiivinen käyttö voi lisätä subjektiivista hyvinvointikokemusta.

\section{SOSIAALINEN MEDIA ITSENSÄ ILMAISUN VÄLINEENÄ}

Ihmisillä on luontainen taipumus sosiaaliseen vertailuun (Festinger 1954). Sosiaalinen vertailu muodostaa meille käsityksen siitä, millä tasolla näyttäydymme ikätovereiden rinnalla pärjäämisen (kykyjen vertailu), tuntemusten (mielipidevertailu) ja käyttäytymisen suhteen. Sosiaalinen vertailu voi näin ollen suuntautua joko ylös- (toinen on parempi) tai alaspäin (itse on parempi) tietyn ulottuvuuden osalta. Sosiaalisen median alustat tarjoavat hedelmällisen pohjan itseilmaisulle ja sosiaaliselle vertailulle, sillä samastumiseen soveltuvia vertailukohteita löytyy ennennäkemättömässä mittakaavassa (Verduyn ym. 2017).

Verratessamme itseämme sosiaalisessa mediassa sellaisiin ihmisiin, jotka suoriutuvat mielestämme itseämme paremmin (ts. sosiaalinen vertailu ylöspäin), altistumme helpommin kateuden ja ahdistuksen tunteille (Ozimek ym. 2020). Sosiaalisen median passiivinen selailu on yhdistetty etenkin tämän tyyppiseen sosiaaliseen vertailuun ja kateuden tuntemuksiin (Verduyn ym. 2015). Viimeaikaiset tutkimustulokset ovat yhdistäneet ylöspäin suuntautuneen sosiaalisen vertailun tärkeistä verkkotapahtumista ulkopuolelle jäämisen kokemuksiin (engl. Fear Of Missing Out, FOMO) (Milyavskaya ym. 2018), ja tyytymättömyyteen omaan kehonkuvaan (Rousseau ym. 2017). Kun keskittyy toisten kykyihin mielipiteiden sijaan, altistaa itsensä helpommin haitallisille tuntemuksille (Yang ym. 2018).

Sosiaalisessa mediassa tapahtuvassa kommunikaatiossa on monia erityisiä piirteitä (esimerkiksi asynkronisuus ja visuaalisuus), jotka tekevät ylöspäin suuntautuvan vertailun ja kateuden tunteet erityisen todennäköiseksi. Sosiaalisen median kanavat tarjoavat monia ominaisuuksia ruusuisen elämän tai menestyksen välittämiseen, niinpä näiden palvelujen käyttäjät kohtaavat useammin menestyksen kuin epäonnistumisten viestimistä (Kross ym. 2013).

Ihmiset, joilla esiintyy masentuneisuutta tai jotka kärsivät alhaisesta itsetunnosta, ovat myös taipuvaisia ylöspäin suuntautuvaan sosiaaliseen vertailuun, mikä saattaa edelleen heikentää heidän hyvinvointiaan (Jang ym. 2016). Lisäksi persoonallisuuden piirteistä neuroottisuus saattaa lisätä ylöspäin suuntautuvaa vertailua ja samalla kateuden tuntemuksia (Rozgonjuk ym. 2019).

\section{TUNTEMUSTEN JAKAMINEN SOSIAALISESSA MEDIASSA}

Tutkimustulokset ovat osoittaneet, että kokiessamme voimakkaita positiivisia 
ja negatiivisia tunteita, olemme motivoituneita jakamaan näitä tuntemuksia myös muille ihmisille (Rimé 2009). Erään teorian (engl. Social Sharing Theory of Emotions) mukaan, tunteiden jakaminen auttaa saavuttamaan sosioemotionaalisia ja tiedollisia tarpeitamme (Rimé 2009). Muilta ihmisiltä saatu sosioemotionaalinen tuki taas auttaa vahvistamaan koettuja tunteita, normalisoimaan kokemuksia, ja nauttimaan positiivisista olotiloista. Neuvojen tai tietojen vastaanottaminen toisilta palvelee tiedollisia tarpeitamme ja auttaa ymmärtämään kokemuksiamme.

Sosiaalinen media mahdollistaa välittömän yhteyden muodostamisen läheisiin (sosiaalisen pääoman vahvistaminen) ja etäisemmin tuttuihin (sosiaalisen pääoman yhdistäminen) henkilöihin (Liu ym. 2016). Sosiaalisen median kautta ihmisillä on mahdollisuus päästä uuden tiedon äärelle, altistua erilaisille näkökulmille, tuntea olevansa osa laajempaa yhteisöä ja saada palautetta, mikä voi tyydyttää ihmisen sosioemotionaalisia (emotionaalinen tuki; tyypillisesti tarjoavat vahvan sitoutumisen) ja tiedollisia (tiedollinen tuki; tyypillisesti tarjoavat heikon sitoutumisen) tarpeita. Niin ikään tutkimuksissa on raportoitu, että ihmisen sosiaalisen pääoman kasvu muodostaa perustan sosiaalisen median aktiivisen käytön myönteisille mielenterveysvaikutuksille (Liu ym. 2019).

Samalla tavalla kuin sosiaalinen media tarjoaa meille uusia mahdollisuuksia sosiaalisen pääoman kasvattamiseen tiedon ja tuen tarjonnalla, antaa tämä ympäristö meidän välittää myös omia tunteita tavalla, joka saattaa loukata muita. Tutkimuksissa on todettu, että sosiaalinen media tarjoaa ihmisille myös vaih- toehtoisen väylän kiusaamiselle, joka vaikuttaa haittaavasti tämän toiminnan kohteena olevien hyvinvointiin (Kowalski ym. 2014).

\section{SOSIAALISEN MEDIAN \\ HYVINVOINTIVAIKUTUKSET}

Tulokset sosiaalisen median hyvinvointiyhteyksistä eivät ole yksiselitteisiä. Vaikka jotkut tutkimuskatsaukset osoittavat, että sosiaalisen median passiivinen käyttö heikentää hyvinvointia, on myös raportoitu johtopäätöksistä, jotka viittaavat erityisesti aktiivisen käytön (esimerkiksi tuki ja positiivinen palaute) mahdolliseen pieneen positiiviseen hyvinvointiyhteyteen. Pitkittäis-, kokeelliset ja meta-analyyttiset tutkimustulokset kokonaisuutena viittaavat siihen, että sosiaalisen median käytöllä on hyvinvoinnin kannalta pikimmiten pieni negatiivinen kuin positiivinen vaikutus (Appel ym. 2020).

Tutkijat ovat erityisesti nostaneet esille verkkoympäristössä tapahtuvan sosiaalisen ylöspäin suuntautuvan vertailun keskeisenä haitallisena vaikutusmekanismina. Huomionarvoista on kuitenkin se, että valtaosa teemaa käsittelevistä tutkimuksista on perustunut poikkileikkausasetelmaan, ja käytännöllisesti katsoen kaikki pitkittäistutkimukset sekä useimmat kokeelliset tutkimukset eivät ole pystyneet vahvistamaan sosiaalisen median ja sen passiivisluonteisen käytön hyvinvointiyhteyttä.

Sosiaalisen median käytön hyvinvointivaikutukset ovat suurelta osin perustuneet sen aktiivisen ja passiivisen luonteen mukaiseen tarkasteluun. Aktiivisen käytön positiivisia hyvinvointivaiku- 
tuksia on selitetty sosiaalisen pääoman kasvulla. Sosiaalisen median käyttöön voi liittyä myös voimakkaita negatiivisia tuntemuksia varsinkin, kun näiden palvelujen passiivinen käyttö saattaa lisätä sosiaalista vertailua ja siihen liittyviä kateuden tuntemuksia, mutta samalla käyttö voi johtaa myös mielialaa kohottavaan inspiraatioon.

Tuoreessa scoping-katsauksessa nostetaan esille tutkimukseen ja käsitteellistämiseen liittyviä puutteita (Valkenburg ym. 2021). Sosiaalisen median käytön karkea määrittely aktiiviseen ja passiiviseen luonteeseen ei esimerkiksi huomioi sitä, missä määrin näihin molempiin luokkiin kuuluva palvelujen käyttö on ollut tyypiltään yksityistä ja julkista vai onko käyttö sisältänyt molempia piirteitä. Näiden asioiden sekoittaminen yhteen voi olla hyvinvointivaikutusten arvioinnin kannalta ongelmallista, koska esimerkiksi sosiaalisen median yksityinen käyttö on yleensä synkronisempaa ja intiimimpää johtaen tästä syystä erilaisiin vaikutuksiin. Lisäksi tutkimuksissa on tarkasteltu sosiaalisen median käyttöä yleensä kokonaismääräisesti huomioimatta käyttökertojen useutta, eikä useissa tutkimuksissa olla huomioitu laajasti sosiaalisen median erilaisia palvelualustoja ja -sisältöjä. Hyvinvoinnin käsitteen monivivahteisuus tarjoaa myös oman haasteensa näiden yhteyksien määrittämiselle ja tutkimustulosten vertailtavuudelle.

\section{SOSIAALISEN MEDIAN} HYVINVOINTIVAIKUTUKSISTA TARVITAAN LISÄYMMÄRRYSTÄ

Aikaisempien tutkimusten valossa sosiaalisen median hyvinvointivaikutukset eivät ole yhdenmukaisia. Tarkasteltaessa sosiaalisen median merkityksiä käyttäjän hyvinvoinnille, voidaan vaikutuksia selittää osittain niiden aktivoimilla psykologisilla prosesseilla, joilla voi olla sekä positiivisia että negatiivisia vaikutuksia hyvinvointiin. Toisin sanoen hyvinvointivaikutukset riippuvat paljolti siitä, miten käyttäjä navigoi näissä ympäristöissä. Psykologisten prosessien lisäksi yksilölliset ja kulttuurilliset erot selittävät sosiaalisen median käyttöön yhdistyviä vaikutuksia.

Tulevaisuudessa tarvitaan lisää tietoa siitä, miten yksilökohtaiset tekijät vaikuttavat sosiaalisen median käyttöön ja niihin liittyviin kokemuksiin. Yksilölliset hyvinvointia suojaavat tekijät (kuten ihmissuhdetaidot ja elämäntavat) sekä emotionaaliselle reagoinnille altistavat haavoittuvuustekijät (kuten murrosikä, stressi ja univaje) voivat vaikuttaa siihen, miten sosiaaliseen mediaan osallistutaan, miten siellä käyttäydytään ja kuinka näiden palvelujen käyttöön reagoidaan. Lisäksi tarvitaan ymmärrystä siitä, miten sosiaalisen median vaikutukset ulottuvat hyvinvoinnin ulkopuolisiin tekijöihin (kuten perhetilanne ja kouluelämä), ja millainen merkitys erilaisilla sosiaalisilla tai kulttuurisilla ympäristöillä voi olla näihin kokemuksiin.

Sosiaalisen median hyvinvointivaikutuksia voidaan selittää näillä esitetyillä potentiaalisilla, taustalla vaikuttavilla mekanismeilla, mutta ne eivät ole ainoita selittämään sosiaalisen median ja subjektiivisen hyvinvoinnin välisiä yhteyksiä. Esimerkiksi tiedollisen ylikuormituksen, verkkopalvelujen aiheuttamien keskeytysten, monisuorittamisen ja kasvokkain tapahtuvan vuorovaikutuksen vähenemisen on raportoitu 
olevan mahdollisia sosiaalisen median käytön hyvinvointiyhteyksien selittäviä mekanismeja.

\section{KiRJALlisuUS}

Appel Markus \& Marker, Caroline \& Gnambs, Timo (2020) Are Social Media Ruining Our Lives? A Review of MetaAnalytic Evidence. Review of General Psychology 24 (1), 60-74. https://doi. org/10.1177/1089268019880891

Baumeister, Roy F \& Leary, Mark R (1995) The need to belong: desire for interpersonal attachments as a fundamental human motivation. Psychological Bulletin 117 (3), 497-529.

Eurostat (2019) Are you using social networks? Eurostat. https://ec.europa.eu/ eurostat/web/products-eurostat-news/-/ EDN-20190629-1 Luettu 22.6.2021.

Festinger, Leon. A (1954) Theory of Social Comparison Processes. Human Relations 7, 117-40. https://doi. org/10.1177/001872675400700202

Jang, Kyungeun \& Park, Namkee \& Song, Hayeon (2016) Social comparison on Facebook: Its antecedents and psychological outcomes. Computers in $\mathrm{Hu}-$ man Behavior 62, 147-54. https://doi. org/10.1016/j.chb.2016.03.082

Kowalski, Robin M \& Giumetti, Gary W \& Schroeder, Amber N \& Lattanner, Micah R (2014) Bullying in the digital age: a critical review and meta-analysis of cyberbullying research among youth. Psychological Bulletin 140 (4), 1073-1137. https://doi.org/10.1037/a0035618

Kross, Ethan \& Verduyn, Philippe \& Demiralp, Emre \& Park, Jiyoung \& Lee David S \& Lin Natalie \& Shablack, Holly \& Jonides John \& Ybarra Oscar (2013) Facebook use predicts declines in subjective well-being in young adults. PLoS One 8 (8), e69841. https://doi. org/10.1371/journal.pone.0069841

Liu, Dong \& Ainsworth, Sarah E \& Baumeister, Roy F (2016) A meta-analysis of social networking online and social capital. Review of General Psychology 20 (4), 369-391. https://doi.org/10.1037/ gpr0000091
Liu, Dong \& Baumeister, Roy F \& Yang, Chia-Chen \& Hu, Baijing (2019) Digital communication media use and psychological wellbeing: A meta-analysis. Journal of Computer-Mediated Communication 24, 259-74. https://doi. org $/ 10.1093 / \mathrm{jcmc} / \mathrm{zmz} 013$

Milyavskaya, Marina \& Saffran, Mark \& Hope, Nora \& Koestner Richard (2018) Fear of missing out: prevalence, dynamics, and consequences of experiencing FOMO. Motivation and Emotion 42, 725-737. https://doi.org/10.1007/ s11031-018-9683-5

Moreno, Megan (2014) Social Networking. Teoksessa Victor C Strasburger, Barbara J Wilson \& Amy B Jordan (toim.) Children, Adolescents, and the Media 3.painos. Thousand Oaks, CA: SAGE Publications.

Nesi, Jacqueline\& Choukas-Bradley, Sophia \& Prinstein Mitchell J (2018) Transformation of adolescent peer relations in the social media context: part $1-\mathrm{A}$ theoretical framework and application to dyadic peer relationships. Clinical Child Family Psychology Review 21 (3), $267-$ 294. https://doi.org/10.1007/s10567018-0261-x

Ozimek, Phillip \& Bierhoff, Hans-Werner (2020) All my online-friends are better than me - three studies about abilitybased comparative social media use, selfesteem, and depressive tendencies. Behaviour \& Information Technology 39 (10), 1110-1123. https://doi.org/10.108 0/0144929X.2019.1642385

Rideout,Vicky \& Robb, Michael B (2019) The common sense census: Media use by tweens and teens. San Francisco, CA: Common Sense Media.

Rimé, Bernard (2009) Emotion elicits the social sharing of emotion: theory and empirical review. Emotion Review 1 (1), 60-85.

Rousseau, Ann \& Eggermont, Steven \& Frison, Eline (2017) The reciprocal and indirect relationships between passive Facebook use, comparison on Facebook, and adolescents' body dissatisfaction. Computers in Human Behavior 73, 336-344. https://doi.org/10.1016/j. chb.2017.03.056 
Rozgonjuk, Dmitri \& Ryan, Tracii \& Kuljus, Joosep \& Täht, Karin \& Scott, Graham (2019) Social comparison orientation mediates the relationship between neuroticism and passive Facebook use. Cyberpsychology Journal of Psychosocial Research on Cyberspace 13 (1). https://doi.org/10.5817/CP2019$1-2$

Statista (2021) Most popular social networks worldwide as of January 2021, ranked by number of active users. https://www. statista.com/statistics/272014/globalsocial-networks-ranked-by-number-ofusers/. Luettu 22.6.2021.

Valkenburg, Patti M \& van Driel, Irene I \& Beyens, Ine (2021) Social media and well-being: Time to abandon the activepassive dichotomy. PsyArXiv Preprints. https://doi.org/10.31234/osf.io/j6xqz

Verduyn, Philippe \& Lee, David S \& Park, Jiyoung \& Shablack, Holly \& Orvell, Ariana \& Bayer, Joseph \& Ybarra, Oscar
\& Jonides, John \& Kross, Ethan (2015) Passive Facebook usage undermines affective well-being: Experimental and longitudinal evidence. Journal of Experimental Psychology: General 144 (2), 480-8. https://doi.org/10.1037/ xge 0000057

Verduyn, Philippe \&Ybarra, Oscar \& Résibois, Maxime \& Jonides, John \& Kross, Ethan (2017) Do social network sites enhance or undermine subjective wellbeing? A critical review. Social Issues and Policy Review 11, 274-302. https://doi. org/10.1111/sipr.12033

Yang, Chia-Chen \& Holden, Sean M \& Carter, Mollie DK (2018) Social media social comparison of ability (but not opinion) predicts lower identity clarity: identity processing style as a mediator. Journal of Youth and Adolescence 47 (10), 2114-2128. https://doi. org/10.1007/s10964-017-0801-6 